\title{
O design como método para a implementação de processos produtivos relacionados com a criação de instrumentos musicais em Portugal: A criação de uma campana de trompete
}

Ermanno Aparo is Professor and Head of Master Integrated Design at the Polytechnic Institute of Viana do Castelo (Portugal). Ermanno has lectured extensively on design project and design strategy at international conferences. He taught at the Lusófona University (Lisbon) and at University School of Arts (Coimbra). He published in international academic journals/conferences. Ermanno is a member of the Research Centre for Architecture, Urban Planning and Design - CIAUD (Lisbon, Portugal) and is also member in several scientific international and national research projects. $\mathrm{He}$ is $\mathrm{PhD}$ in Design from Aveiro University (Portugal) with a scholarship of Foundation for Science and Technology (Portugal) and has a Master in Design from the Domus Academy di Milano (Italy). Ermanno Aparo performs strategy consulting and implementation in Product Design and Development for European companies and participated in worldwide exhibitions. He is also an architect from Architecture Faculty of Palermo (Italy). Currently, his research is focused on creating links between music and design. <aparo@estg.ipvc.pt>
Resumo Este trabalho é parte integrante de um projeto de investigação e tem como objetivo demonstrar a competência do Design para ler e interpretar os materiais e os processos de um contexto produtivo, para criar produtos sustentáveis, criativos e inovadores. Nomeadamente, trata-se da escolha de desenvolver produtos de alta prestação no âmbito dos instrumentos musicais. Em termos metodológicos, utiliza-se o método de co-design para fundamentar o desenvolvimento de uma componente de uma trompete. 0 ciclo produtivo complexo de uma componente de um instrumento musical pode trazer benefícios, quer para o processo, quer para os atores envolvidos - artesãos, designers, músicos e pequenas indústrias. Com esta investigação espera-se demonstrar que o designer responsável é capaz de deslocar e orientar experiências, rentabilizando processos já existentes a favor de novos produtos. A criação de uma campana para uma trompete orientada, quer para as problemáticas relacionadas com as performances acústicas e musicais, quer para a temática inovadora de criar um instrumento de sopro no âmbito dos metais, torna esta investigação importante para demonstrar novos âmbitos de desenvolvimento sustentável que abrangem as áreas da música e do design.

Palavras chave Design de instrumentos musicais, Design e Sistemas territoriais, Co-Design, Design tático, Sistema de produto, Design by Drawing, Craft evolution, trompete. 
A criação de uma campana de trompete

Fernando Moreira da Silva is a researcher at CIAUD - Research Centre in Architecture, Urbanism and Design, being also its President (Portugal), honorary researcher at Surface - Inclusive Design Research Centre, University of Salford (UK), full professor in design at the Faculty of Architecture of the University of Lisbon (FA/ULisboa), Portugal, with specialization in Visual Communication Design, Inclusive Design and Color. He is a Member of the Senate of the University of Lisbon, President of the Scientific Board and coordinator of the $\mathrm{PhD}$ in Design of the FA/ULisboa. For the last years he has performed as panel coordinator for doctoral and postdoctoral grants in Design, Architecture and Urbanism at FCT - Foundation for Science and Technology of Portugal, International consultant of CNPq - National Council of Scientific and Technological Development (Brazil) and co-coordinator of the International PhD Degree in Design and Innovation, University of Naples (Italy). Invited professor at several foreign universities in Brazil, Italy, Spain and Hong Kong, he has supervised to more than 70 master dissertations and $50 \mathrm{PhD}$ theses, being a member of the Scientific Committees of several international scientific journals.

<fms.fautl@gmail.com>

\section{Design as a Method for the Implementation of Productive Processes Related to the Creation of Musical Instruments In Portugal: The Creation of a Trumpet Bell}

Abstract This work is an integral part of a research project and aims to demonstrate the competence of Design to read and interpret the materials and processes of a productive context to create sustainable, creative and innovative products. In particular, it is the choice to develop high-performance products within the scope of musical instruments.

In methodological terms, the co-design method is used to support the development of a component of a trumpet. The complex productive cycle of a component of a musical instrument can bring benefits both to the process and to the actors involved - artisans, designers, musicians and small industries.

With this research it is hoped to demonstrate that the responsible designer is able to move and guide experiences, profiting already existing processes in favor of new products. The creation of a bell for a trumpet oriented, both for the problems related to acoustic and musical performances, and for the innovative theme of creating a wind instrument in the field of metals, makes this research important to demonstrate new spheres of sustainable development that cover the areas of music and design.

Keywords Musical Instrument Design, Design and Territorial Systems, Co-Design, Tactical Design, Product System, Design by Drawing, Craft Evolution, Trumpet. 
Liliana Soares is a professor at the Polytechnic Institute of Viana do Castelo (Portugal), and since 2013, has been the Head of the Product Design division. She is a member of the Research Centre Architecture, Urban Planning and Design in the Faculty of Architecture, Lisbon and a member of the Research Institute for Design, Media and Culture, University of Aveiro (Portugal). She has lectured on design theory and design thinking at international and national conferences and has published in international academic journals as well as participated in design fairs. Between 2009 and 2012, she received a scholarship from the Foundation for Science and Technology (Portugal) to develop her PhD in Design at University of Aveiro (defended in 2012). In 1999, she received a scholarship from the Euro-Arab Foundation Institute (Spain) to develop her Master's in Management and Cross Culture ventures at the Euro-Arab Management School (Spain). She is a designer from the Faculty of Architecture, TU Lisbon (1998). Liliana Soares is co-author of the book 'Sei progetti in cerca d'autore of Alinea Editrice', (2012). <lsoares@estg.ipvc.pt>

\section{Introdução}

Existem diversos projetos de inovação que são determinados por ações que começam pela análise do território, rentabilizando os recursos produtivos existentes e determinando a criação de produtos sistémicos. A oscilação da procura tem sido determinante na economia de estruturas produtivas orientadas para os processos e menos focadas nos produtos. Para algumas empresas estes processos têm sido entendidos como processos de "de-verticalização" [1], provocando a integração e a distribuição das empresas em sistemas de redes, geograficamente bem definidos, mais flexíveis e, por esta razão, capazes de serem integrados em estruturas produtoras de inovação. Os processos relacionados ao desenvolvimento de um produto são articulados num sistema de redes, que não é constituído apenas por produtores mas por outros atores úteis para este processo como, por exemplo, os utilizadores.

Ao designer cabe a responsabilidade de articular estes processos, determinando métodos e práticas que permitam uma interação eficaz entre os vários intervenientes. Porém, um processo como este que, se pode definir de co-design, não se deve limitar à ação do designer enquanto dinamizador de uma ação. Como afirma Ezio Manzini [2], o designer deve ter uma atitude mais interventiva. Por um lado, ouvindo os contributos de todos os interlocutores transformando-os em vantagens do projeto. Por outro lado, utilizando a cultura de projeto de modo transversal, cruzando-a com fatores externos que surjam no faseamento do processo. Neste sentido, é, igualmente, possível suportar este estudo com o conceito de Design Tático [3], um método projetual capaz de gerar inovação. Um método que permite a transferência de conhecimento e competências determinadas pela troca de informação que rentabilizam as capacidades produtivas de cada um dos elementos que constituem uma rede produtiva.

Neste estudo, apresenta-se o caso da produção de uma campana de trompete "em peça única", absolutamente inovadora para o contexto português. Trata-se da escolha de beneficiar de uma rede de algumas entidades produtivas de natureza distinta. Com esta ação pretende-se constituir uma rede produtora de um produto complexo, designadamente, uma campana de uma trompete. Este projeto piloto pretende ser a base de partida para uma reflexão projetual à posteriori capaz de demonstrar as potencialidades que o design tem, em termos de constituição de um Sistema Territorial para o desenvolvimento de um produto inovador. Neste caso especifico, na área dos instrumentos musicais.

\section{Premissas do projeto}

A criação de um instrumento musical pode ser enquadrada como o desenvolvimento de um produto sistêmico, uma atividade multidisciplinar [4] que nasce num contexto artesanal para evoluir para uma vertente industrial. 
Em Portugal, ao longo dos séculos, nunca foi possível estabelecer uma produção sistemática de instrumentos musicais na área dos metais. A pesquisa realizada durante esta investigação apurou poucos casos, muito pontuais, como o de algumas "charamelas reais" construídas em meados de 1700 [5] e outros exemplos construídos entre Lisboa [6] e Porto [7] [8] [9], num período entre a segunda metade de 1800 e a primeira metade de 1900. Contemporaneamente, em Portugal desenvolve-se uma atividade produtiva relacionada ao desenvolvimento de instrumentos musicais populares como as cornetas ou os funis, que eram utilizados, quer para acompanhar danças, quer para emitir sinais para as atividades comerciais nômadas que povoavam os tecidos urbanos [10].

Hoje, embora em Portugal e em particular no norte do País, haja uma forte tradição musical de bandas e orquestras, não existe a produção de aerofones da família dos metais. Este fato provoca que se recorra à importação destes produtos, em particular, de países Asiáticos e dos Estados Unidos.

Na Europa, no âmbito dos instrumentos musicais de sopro e, em particular, nos metais, existem diferentes exemplos de empresas a produzir este tipo de instrumentos. Muitas são caraterizadas pela implementação de processos que cruzam a produção industrial com a produção artesanal. Embora algumas empresas tenham fechado e outras tenham sido absorvidas por grupos internacionais, no território Europeu ainda permanecem empresas produtoras de instrumentos musicais, na área dos sopros, que conseguem afirmar os próprios produtos. Estas empresas aparecem concentradas no centro Europa, com uma grande percentagem na Alemanha que detém, ainda hoje, uma grande tradição nesta área. Durante o desenvolvimento desta investigação foi possível determinar que a maioria das empresas que produzem este tipo de instrumentos são de caráter artesanal (em amarelo no diagrama da fig.1). As empresas que determinam uma produção mais industrial (em preto no diagrama da fig.1) são em número muito reduzido.

Diversos autores [11][12][13] sustentam que a transferência de conhecimento é um valor fundamental para o desenvolvimento de uma área produtiva ou de uma tecnologia. Trata-se de um processo que determina a importância da disciplina do Design como veiculador de experiências que geram processos coletivos de desenvolvimento.

Figura 1 Distribuição da produção de metais na Europa e ideograma do fluxo informativo do projeto.

Fonte Ermanno Aparo, 2016.

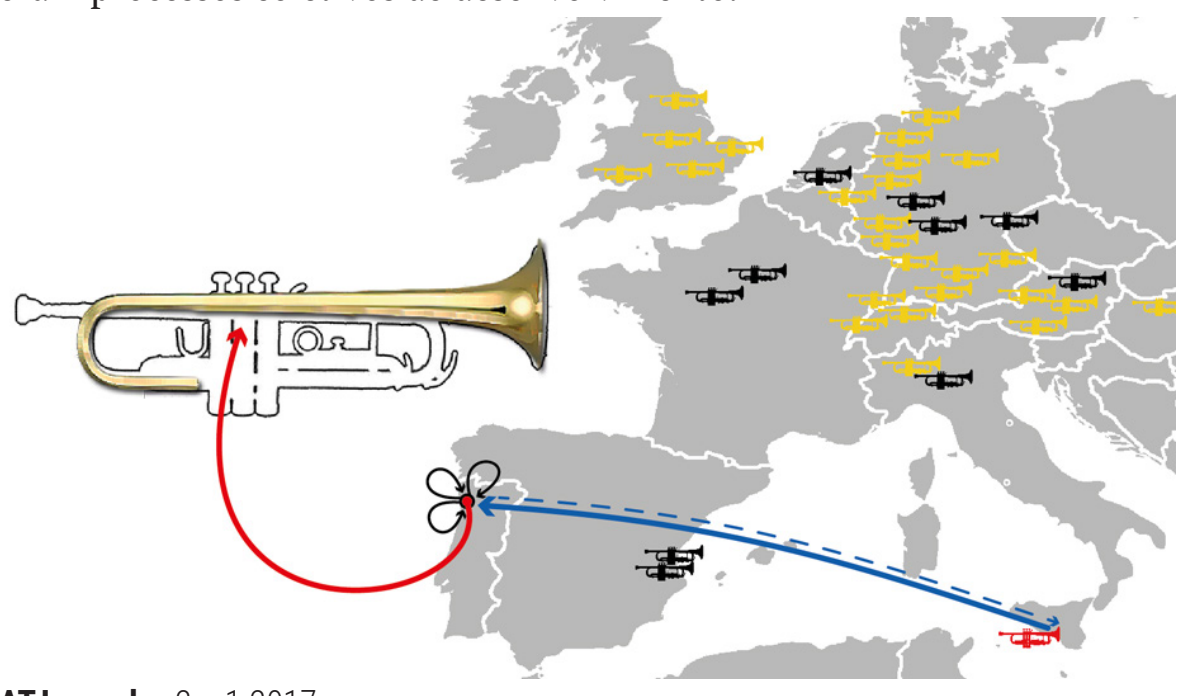


Considerando que o objetivo deste estudo é o desenvolvimento de um instrumento musical, quer utilizando um processo criativo de transferência de conhecimento, quer rentabilizando os recursos das estruturas produtivas locais, procurou-se um artesão que dominasse as técnicas de produção dos instrumentos de sopros. Este contato poderia proporcionar o acesso às técnicas artesanais para, posteriormente, transferi-las para o território português. Neste sentido, contatou-se um artesão Siciliano (Itália), Vito di Grigoli, que há mais de 10 anos constrói, quase na totalidade, instrumentos de sopros. A ligação com o artesão Vito di Grigoli poderia determinar um processo de transferência de noções e de partilha de experiências, determinando a implementação de um processo produtivo de um instrumento musical em Portugal. Esta conexão poderia permitir, ainda, o acompanhamento e a verificação dos progressos do projeto em Portugal, designadamente, o artesão italiano poderia beneficiar das experiências realizadas na produção em Portugal para melhorar os seus próprios processos (Figura 1).

\section{Âmbito do projeto}

A estrutura de um produto complexo como um instrumento musical, pode ser pensada como um sistema de produto constituído por diferentes componentes que definem pattern projetuais [14]. Cada pattern é o resultado de uma forte interação entre os vários intervenientes. No caso especifico de uma trompete, podemos pensar em subdividir este instrumento em patterns qualificadas, quer pela função-prática que desenvolvem no instrumento, quer pelo tipo de processo produtivo. A subdivisão é a mesma que é utilizada para explicar o funcionamento de uma trompete, ou seja:

- A campana;

- As bombas;

- Os pistões;

- O leadpipe, (tubo cônico que vai do bocal até a bomba geral) o receptor (tubo onde é colocado o bocal) e o bocal.

A escolha da primeira pattern assentava no método que o processo deveria acompanhar e não numa escolha autônoma. Neste sentido, pareceu pertinente deixar que a escolha fosse realizada depois de uma visita ao atelier do artesão siciliano em Cammarata, na província de Agrigento, no sudoeste da Sicília, em Itália. Decidiu-se começar pela campana, no sentido que segundo o parecer do artesão italiano, a campana reunia mais dificuldades, tornando-a uma das partes mais difíceis de se realizar e, consequentemente, a sua resolução poderia revelar-se um ponto de partida para o desenvolvimento das outras partes, aparentemente, mais simples. A complexidade da campana deve-se, igualmente, ao fato de que o seu processo de fabrico reúne fases e processos presentes nas outras componentes. Esta componente seria a pattern ideal para entender a prossecução do projeto, antecipando problemáticas futuras. 

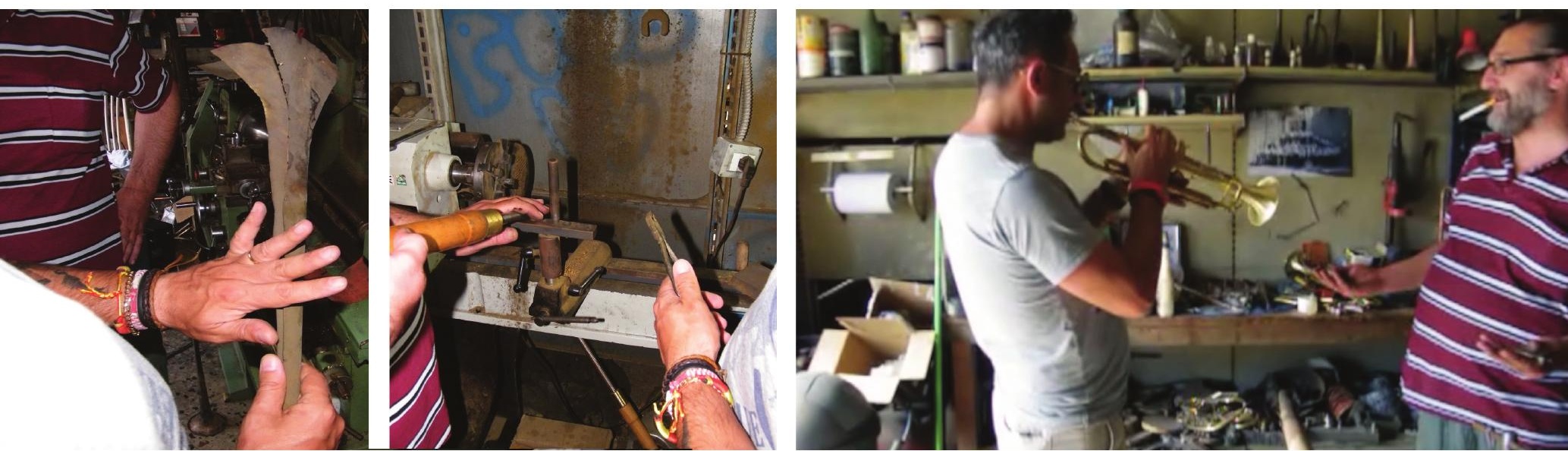

Figura 2 Visita ao atelier de Vito di Grigoli em Cammarata - Sicilia. Fonte Eugenio Aparo, 2015.

Em Agosto de 2015 realizou-se uma visita ao atelier de Vito di Grigoli que permitiu entender que fases do processo poderiam ser implementadas e de que forma deveriam ser desenvolvidas. Neste sentido, foram concretizadas algumas escolhas para facilitar a transferência do processo Italiano no contexto Português. O material escolhido foi a chapa de cobre (espessura 0,5 e 0,6 $\mathrm{mm}$ ), embora a campana de trompete seja, normalmente, produzida em latão $(\mathrm{Cu}+\mathrm{Zn})$. Por um lado, neste estudo, a escolha de uma campana em cobre $(\mathrm{Cu})$ deve-se, principalmente, à dificuldade de encontrar em Portugal chapas de latão nas combinações utilizadas como, por exemplo, a gold brass $(85 \% \mathrm{Cu}+15 \% \mathrm{Zn})$ ou a red brass $(90 \% \mathrm{Cu}+10 \% \mathrm{Zn})$. Por outro lado, este tipo de escolha reflete uma tendência de vários séculos, quer em exemplares dos Séculos XIII e XIV, na Grã Bretanha, Alemanha, Suíça e França [15], provavelmente, de influência muçulmana e importados durante as cruzadas, quer em exemplares utilizados durante cerimónias ou ações de cavalaria do Séc. XVIII de produção alemã da família Köhler [16][17].

Em 1938 a empresa alemã Conn desenvolve uma tecnologia, permitindo que a campana em cobre fosse produzida por uma deposição de cobre obtida electroliticamente [18]. O processo, que mostrava uma distribuição mais regular dos cristais em comparação da estrutura de uma campana produzida com um processo clássico, foi abandonado por motivos não completamente claros. Uma análise exterior permite explicar que os motivos de relacionavam ao tempo do processo e à pouca uniformização da espessura das paredes ao longo da peça, determinando uma projeção sonora, provavelmente, pior do que a obtida com o processo clássico por martelagem.

Hoje, no desenvolvimento de um instrumento musical de trompete, muitas marcas optam por apresentar produtos com campanas em cobre, garantindo um som mais cheio e completo e uma maior projeção. Entre estas marcas salientam-se: 
- a Kanstul com os modelos ZKT 1500 e ZKT 1601;

- a Schilke com os modelos HC2 L, B5 e B6;

- a Calicchio com a 3/9 Copper Solo;

- a Zeus com os modelos ZTR 900 C-RL, ZTR 900 C-ARL, ZTR 900 C-ARLX e ZTR 900 C-RW;

- a Austin com o modelo 470LT.

Além destes casos, existem muitas outras marcas que customizam um instrumento com o acréscimo de uma campana em cobre.

\section{Método}

\section{Faseamento}

A visita ao atelier do artesão italiano e a revisão bibliográfica permitiram determinar que o processo de criação de uma campana de trompete fosse, estruturalmente, dividido em cinco fases:

- Fase preparatória: na qual se organizavam todas as ferramentas que seriam necessárias para o processo;

- Passagem da forma plana para a forma cônica;

- Configuração mecânica;

- Curvatura da campana;

- Acabamento (por motivos de economia do processo global e de uniformização com as outras componentes, esta fase será desenvolvida num segundo momento, juntamente a outros componentes do instrumento).

Considerando o cariz experimental do projeto e a forte componente de inovação do processo, descrito nas suas várias fases deste estudo, o faseamento do projeto orientou-se para o processo e não para o produto [19]. Os processos desenvolvidos determinariam peças diferentes, tendo sido admitido que, em cada fase, pudessem entrar soluções diferentes com resultados distintos. Desta forma seria possível construir uma análise, numa sequência produtiva, escolhendo o processo que geraria as hipóteses satisfatórias [20] que contribuiriam para o desenvolvimento de uma solução eficaz de campana para trompete.

\section{Fase preparatória}

Esta fase preparatória caracteriza-se pela preparação de todos os instrumentos úteis para a produção da componente campana.

Primeiramente, foi necessário a criação de um molde, a utilizar nas fases (b) e (c) para definir a forma da campana. Neste sentido, o artesão italiano cedeu o desenho de uma forma para, posteriormente, ser realizada 
em Portugal. Normalmente, estas formas servem, quer para bater a chapa (seja a quente, seja a frio), quer para servir de base para repuxar o material para cima, concedendo-lhe a forma definitiva. As caraterísticas e os tipos de solicitação da forma, ao longo do processo, determinaram a necessidade de recorrer a uma empresa de metalomecânica que desenvolve o seu serviço, em particular, na área das reparações navais. Uma análise morfológica prévia da forma do molde realizada, conjuntamente, com os responsáveis da empresa, determinou que esta poderia ser produzida em duas peças enroscadas. Esta solução permitiria trabalhar com metais diferentes. Por um lado, a parte mais longa e estreita seria em aço cromo-níquel (34 CrNiMo 6), assegurando uma maior resistência para uma estrutura fina, quer em termos de solicitações mecânicas, quer em termos de solicitações térmicas, garantindo a conservação da forma ao longo do processo. Por outro lado, a parte mais grossa não necessitava deste tipo de material, em particular, a sua morfologia não criava problemas de empeno como a outra parte e, consequentemente, poderia ser realizada em aço mais comercial (CK 45), descendo os preços de produção da peça. A criação do molde em duas partes permitia que, no futuro e conforme as exigências que se apresentassem em termos de prestações do instrumento, se pudesse alterar apenas a parte terminal da forma, criando, por exemplo, uma campana mais fechada, mas mantendo a parte mais reta idêntica ou constante.

Para realizar o molde foi necessário o redesenho da forma num programa de CAD que possibilitou a produção da peça num torno de controlo numérico, garantindo a precisão e a redução do tempo. Foram pedidos orçamentos a outras empresas que proporcionaram configurações diferentes e preços mais elevados do que os da empresa escolhida. A configuração escolhida revelou-se mais vantajosa, mais funcional e, também, mais barata do que aquela sugerida pelo artesão italiano.

As fases (b) e (d) do processo seriam acompanhadas por um latoeiro residente no norte de Portugal, nomeadamente, na região do Minho, e que foi escolhido devido à sua experiência na criação produtos musicais como, por exemplo, clarins, trombas naturais e cornetas de gramofones. Esta escolha assenta, igualmente, nos processos utilizados pelo latoeiro português, similares a alguns processos necessários à criação de uma campana. $\mathrm{O}$ artesão em questão, Francisco Liquito, continua a profissão do pai, aproveitando tipologias de instrumentos e técnicas que herdou e que aplica na sua produção. $\mathrm{O}$ escasso conhecimento acerca da música e deste mundo produtivo determinou que os instrumentos criados por Francisco Liquito tenham uma escassa performance sonora. De fato, os instrumentos musicais produzidos por este artesão são apenas adquiridos pelo seu valor simbólico. Neste sentido, a razão principal pela qual o artesão aceitou entrar neste desafio baseia-se na possibilidade concreta de poder, a médio e a longo prazo, criar objetos portadores de uma performance sonora e não apenas de valor semântico. A análise comparativa entre o processo acompanhado pelo artesão Vito di Grigoli, na Sicília (Itália) e o processo desenvolvido pelo artesão 
Francisco Liquito, no Minho (Portugal), permitiu estabelecer que as fases (b) e (d) pudessem ser desenvolvidas, beneficiando das ferramentas que o artesão português, normalmente, utilizava. Contudo, seriam necessárias algumas ferramentas que determinariam algumas especificidades do processo em causa, cuja pertinência e presença, pareceu incontornável para o correto desenvolvimento do processo. Algumas das novas ferramentas foram desenvolvidas pelo artesão Francisco Liquito, enquanto que outras ferramentas foram desenvolvidas pela equipa de investigação de propósito para o projeto. Assim, foram realizados uns malhos de madeira (Figura 3):

- um malho de faia, a mesma madeira utilizada pelo artesão italiano;

- um malho em mogno, uma madeira mais dura e densa do que a madeira anterior, escolhida em função de experiências realizadas durante o processo desenvolvido.

- uma outra ferramenta muito específica, ou seja, um alicate para criar dentes na chapa, foi obtida modificando uma ferramenta, normalmente, utilizada para cortar chapas.
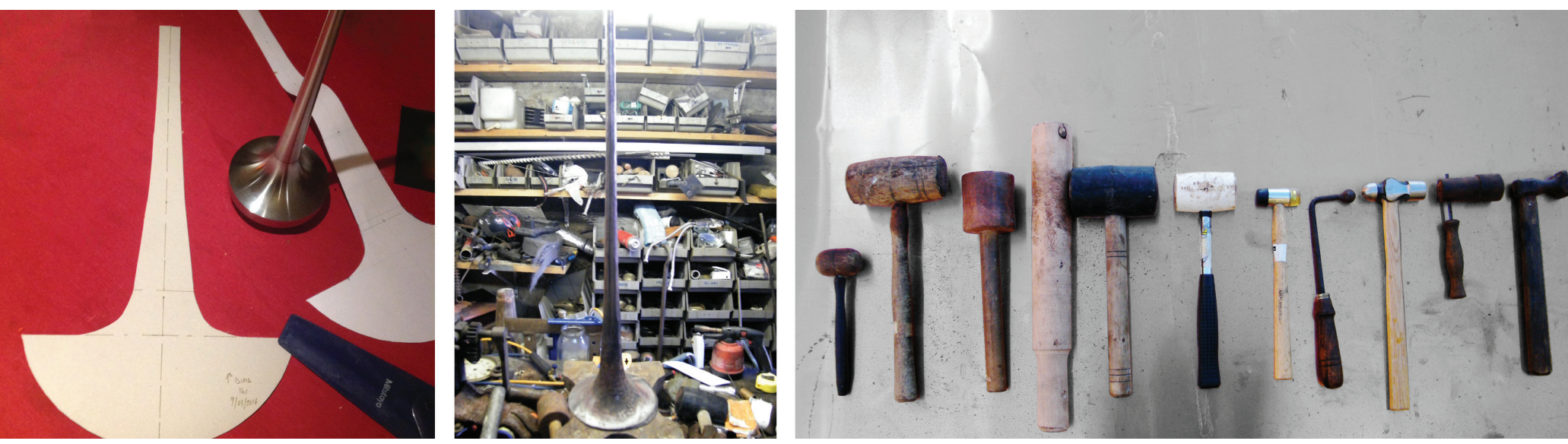

Figura 3 Da esquerda para direita: Molde em aço e 2 planificações da campana. Cópia do molde em chumbo. Malhos e martelos utilizados no processo

Fonte Ermanno Aparo, 2016.

Nesta fase foram também desenvolvidas 4 planificações para a chapa (fig.3). Uma base que serviria para cortar a chapa e que, depois de batida e repuxada, daria a campana. Durante o processo de transformação a chapa acabaria por seguir diferentes curvaturas, algumas delas implementadas em sentido contrário uma das outra. Deste modo, a complexidade do processo necessitou de um método misto combinando os dois métodos descritos por Jonh Chris Jones [21]: o método do Design-by-Drawing (implementado com o desenho manual e com o desenho desenvolvido em CAD) e o método do Craft Evolution, traduzido numa técnica do próprio artesão que levava a produzir uma cópia do molde em chumbo (Figura 3) e que, posteriormente, 
é aberto e distendido. Embora se tenha chegado a 4 planificações, o desenvolvimento das fases (b) e (c) permitiu entender que o tipo de planificação não era fixo, dependendo, igualmente, da forma de trabalhar a chapa.

\section{Passagem da forma plana para a forma cônica}

Nesta fase a folha de cobre é transformada numa espécie de funil. Num primeiro momento, a chapa é cortada com uma tesoura específica. De seguida, a chapa é dobrada e fechada, unindo as abas com um processo de brasagem e, posteriormente, batida com martelos e malhos (Figura 4). 0 sucesso nesta fase seria dependente de cada momento do processo de transformação e, na sequência que se lhe iria produzir, cada alteração poderia determinar mutações no comportamento da campana.

A produção de uma campana em cobre é determinada por um controlo muito cuidadoso do comportamento e das propriedades do cobre. Para poder ser trabalhada, a chapa deveria ser submetida, constantemente, a um processo de re-cozedura. 0 excesso de calor poderia comprometer as propriedades acústicas do material e, consequentemente, da campana. Outro fator a ter em conta na transformação da chapa relacionava-se com a união das abas, determinando um volume que ficasse, suficientemente, largo - de forma a não criar rasgos - e estreito - de forma a aderir ao molde sem escorregar quando fosse submetido a um torno mecânico na fase (c).

Nesta fase, o processo desenrolou-se da seguinte forma. A chapa é cortada, acompanhando uma forma da cartão e é recozida, uma primeira vez, de forma a melhorar a sua ductilidade e a correr menos riscos, nomeadamente, evitando que a chapa se possa rasgar ao longo do processo. Uma vez que a chapa arrefeceu são praticados alguns dentes numa das abas, de forma a garantir a ligação entre as partes durante a brasagem. Depois, chapa soldada é batida para alcançar a forma desejada. Esta operação é desenvolvida recorrendo a martelos e a malhos, utilizando como suporte duas bigornas diferentes e o molde. A conclusão desta fase termina quando a chapa assume uma forma de funil e consegue vestir o molde, sem apresentar folgas ou pelo contrário, zonas apertadas. $O$ encaixe da peça no molde determinava a possibilidade a passagem para a fase (c) que prevê a fixação do molde e da chapa num torno mecânico para esta ser repuxada. Ao longo desta fase foram produzidas 6 (seis) peças, sendo que, só 4 (quatro) delas passaram para a fase seguinte. Nesta fase, a primeira das 4 (quatro) peças produzidas, foi cortada em três partes, para analisar o comportamento da chapa no interior. As outras duas não reuniam as condições mínimas para passarem à configuração mecânica.

O parecer do artesão italiano relativamente ao processo realizado e a análise a outros processos permitiram entender as vantagens e as desvantagens do processo aplicado. Considerando que alguns dos resultados obtidos não eram os esperados, quer em termos de acabamentos, quer em termos de execução, decidiu-se voltar recuar, alterando alguns procedimentos e mantendo outros. 

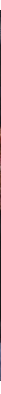

Figura 4 Da esquerda para direita: Corte da chapa. Soldagem.

Chapa fechada. Chapa batida com malho em madeira.

Fonte Ermanno Aparo, 2016.

Um dos pontos a corrigir foi o número de dentes das abas que poderiam ser reduzidos, concentrando a sua presença em algumas zonas mais estratégicas. Esta solução permitiria que o processamento da chapa fosse mais rápido e que o alisamento da superfície interior fosse menos problemático. Durante o processo de brasagem a vareta em cobre foi substituída por uma vareta em prata, que determinava a introdução de um material mais flexível o que não arriscava de comprometer a ligação quando a peça era batida. Posteriormente, foi realizada uma experiência com uma vareta de latão, para entender se esta possibilidade poderia ser uma solução melhor, compondo um meio caminho entre a dureza da vareta em cobre e a flexibilidade da vareta em prata, com a vantagem de ser mais barata do que a vareta em prata. Relativamente às duas primeiras chapas, optou-se por fechar a chapa para depois prosseguir com a percussão da chapa. As duas chapas seguintes foram fechadas à medida que a superfície era conformada. Num primeiro momento, estas duas maneiras de proceder causaram que, de um lado, o fecho da superfície determinasse o risco da peça quando fosse colocada no molde, considerando que o batimento da superfície podia, facilmente, provocar fendas ou rasgos na superfície. Do outro lado, uma superfície com folgas em relação ao molde poderia prejudicar o processo desenvolvido na fase (c). Desta forma, nas últimas 2 (duas) peças, optou-se por um processo gradual, depois de ter procedido com uma fase de batimento, soldando, topo a topo, a parte mais estreita da campana e fechando a parte mais larga, num segundo tempo.

Durante o desenvolvimento das 6 (seis) peças foram experimentadas diferentes combinações, batendo a chapa com diferentes ferramentas (martelos e/ou malhas) e, proporcionado diferentes graus de re-cozedura do material. No final de cada fase de cozedura e depois da peça ter sido batida, registou-se que se deveria realizar uma prova empírica de ressonância, de forma a garantir que a re-cozedura não tivesse comprometido a sonoridade da campana e, consequentemente, a sua funcionalidade. 


\section{Confıguração mecânica}

Para definir a forma da campana seria necessário implementar uma repuxagem da chapa, para que ela assentasse perfeitamente no molde. Este tipo de operação requeria uma maquinaria própria e um operador que soubesse aplicar esta técnica, para alcançar o resultado desejado sem estressar o material e sem alterar as propriedades da componente. Numa primeira análise aos recursos existentes no território, evidenciaram-se algumas dificuldades, nomeadamente, na escolha de uma oficina ou de um artesão para pudesse repuxar a peça. Este acontecimento sucede, por um lado, porque são poucos os profissionais que ainda desenvolvem esta técnica. Por outro lado, porque os artesãos que estão no ativo não têm maquinaria apropriadas ao processo relacionado à produção de uma campana. Na maioria dos casos, os tornos para repuxar metais eram de dimensões muito reduzidas e os sistemas para prender o molde (buchas) não eram adaptados ao molde que tinha sido desenvolvido.

A análise aos possíveis parceiros que poderiam permitir o desenvolvimento desta fase de projeto, potenciou o regresso à empresa metalomecânica que tinha desenvolvido o molde, pois este tinha sido produzido num torno a controlo numérico. Após uma conversa prévia com os responsáveis da empresa o acesso à oficina foi aberto para se proceder ao desenvolvimento desta fase experimental.

A primeira experiência foi realizada com uma prensa hidráulica com pistão vertical. Com esta maquina pretendia-se obter uma melhor definição da superfície da campana, reduzindo as operações necessárias na repuxagem no torno mecânico. A operação consistia em colocar o molde com a peça dentro por baixo do pistão, por baixo do molde era posto um bloco cilíndrico de chumbo com um furo no meio do mesmo diâmetro da peça na zona mais fina. Ao empurrar o molde e a peça verticalmente, o pistão obrigava-os a passarem pelo buraco da peça em chumbo que iria rasgar-se. Simultaneamente, ao empurrar a peça para cima do molde, melhorava-se, repuxando, a superfície da peça. A prova executada com a primeira peça acabou por determinar a presença de umas rugas, sinal evidente de que a peça era demasiado larga em comparação com o molde.

A segunda peça não requeria esta fase por ter uma superfície mais regular e com menos folgas em relação ao molde, passando, diretamente, para a maquinação no torno mecânico. A primeira operação a ser desenvolvida foi o alisamento e a regulação da superfície da peça no seu interior, tentando retirar as irregularidades e aumentar a conicidade da parte terminal da campana. Para desenvolver esta operação foi necessário enfiar uma anilha de nylon na peça, para que esta pudesse ser presa na bucha do torno. Depois, a parede interna da peça, no seu lado mais aberto, foi trabalhada com a ajuda de uma goiva de braço. 

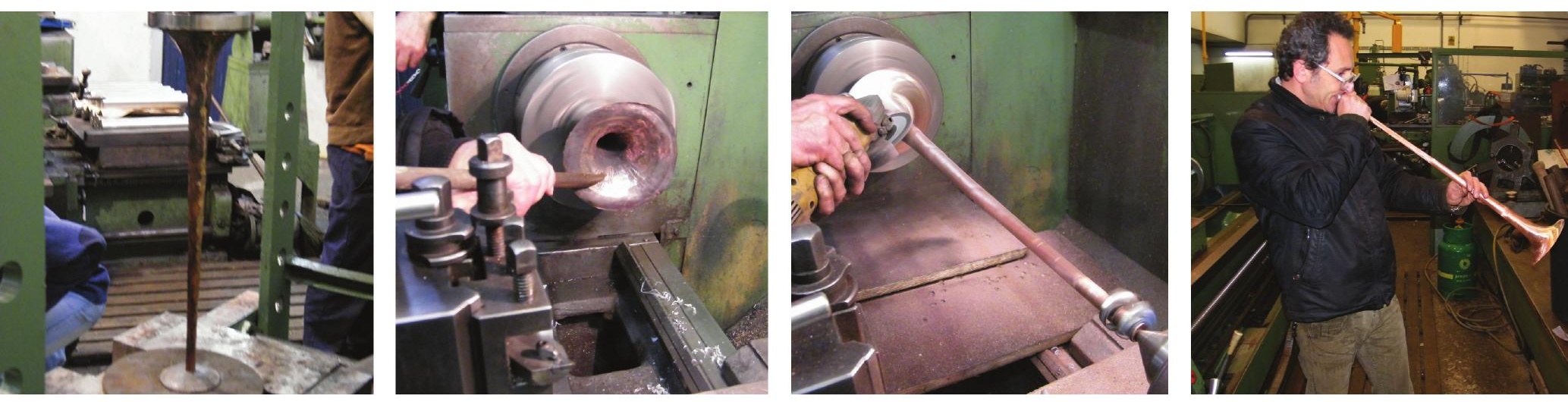

Figura 5 Da esquerda para direita: Peça no pistão hidráulico. Repuxagem da peça no torno com goiva. Acabamento com rebarbadora. Teste da campana.

Fonte Ermanno Aparo, 2016.

Depois desta operação, passou-se para a fase de repuxar a peça. Para isto, foi necessário inserir, novamente, a peça no molde que serão fixados entre a bucha e o contraponto do torno. Uma vez fixado, o conjunto molde/ peça era rodado pelo torno e repuxado com a ajuda de diferentes tipos de goivas de braço. Esta fase foi concluída com o acabamento da superfície com lixas e discos abrasivos. Esta fase permitiu perceber que:

- A prensa poderia ser substituída acrescentando uma repuxagem manual à fase (b) e utilizando uma barra de metal com fieiras manuais. Embora esta técnica seja antiga e muito trabalhosa, ela é ainda implementada por algumas empresas [22] que acreditam e defendem que a qualidade dos instrumentos produzidos passa pela produção e por processos, eminentemente, artesanais.

- O torno disponibilizado pela empresa, não sendo um torno de repuxagem, não era equipado com os apoios necessários para poder puxar as ferramentas contra da superfície. Esta carência não possibilitava exercer a força suficiente na superfície da peça, atrasando o trabalho ou comprometendo o resultado final. Outro fator de relevância que evidenciou esta fase foi a necessidade de criar uma fixação de forma que durante o processamento a peça não deslizasse sobre do molde. Os processos de acabamento foram implementados com lixas e com uma rebarbadora com um disco abrasivo, que se revelou muito violento, podendo danificar a superfície da peça. Neste caso, e depois se terem analisado casos de outras empresas [23], foi possível entender que, a melhor solução para implementar os acabamentos na peça, seria com um pano ou uma esponja abrasiva que se tornaria menos violenta. Um dos fatores que pareceu determinante na rotação do torno foi a velocidade que, no caso da empresa em questão, pareceu insuficiente. 
Figura 6 Da esquerda para direita: Repuxagem da com martelo no torno. Repuxagem da peça no torno com goiva. Fonte Ermanno Aparo, 2016.
Neste sentido, optou-se por implementar o processo desta fase num outro contexto produtivo, nomeadamente, numa oficina de reparações e assistência de equipamentos domésticos. 0 gerente/proprietário tem um torno mecânico e um torno de madeira, cujas caraterísticas serviam, adequadamente, para repuxar a peça. Neste caso, duas peças que não passaram totalmente pela fase (b) mas que pararam antes de permitir que a peça encaixasse no molde, foram trazidas para esta experiência. Pretendia-se evitar inúteis restrições que comprometessem a acústica desta componente. Assim, as duas peças foram trazidas para um primeiro torneamento, de forma a alargar a boca com um processo que já tinha sido aplicado na experiência da empresa anterior.

A esta fase seguiu uma etapa de batimento da parte mais larga da campana, com malhos e martelos, que permitiram, finalmente, passar para a fase de repuxagem. A operação de repuxagem acompanhou a utilização de um lubrificante que, conforme informação obtida durante a pesquisa, assentou na escolha de uma cera. A escolha da cera assentou no parecer, obtido junto dos artesãos, durante a fase de pesquisa.
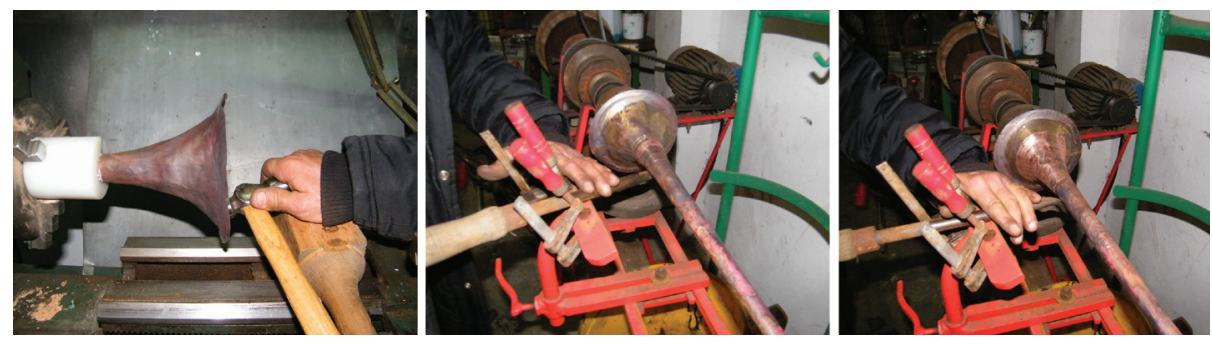

Como consequência, quer dos resultados obtidos na experimentação anterior, quer da conversa com o artesão siciliano, escolheu-se substituir o processo dos acabamentos com rebarbadora, utilizando uma lixa de água muito fina (com gramagem de 1000g) e uma esponja abrasiva, normalmente utilizada para limpezas de tachos ou panelas. Este processo prosseguiu com a criação de uma orla - na parte mais larga da peça - obtida pelo redobramento da chapa - por cima de um arame - e que foi, depois, soldada com estanho. No final, foi, novamente, efetuado um acabamento na zona da orla para eliminar as imperfeições. A orla foi obtida utilizando um tubo, com uma ranhura, que permitiu a dobragem da chapa. Posteriormente, recorreu-se a uma ferramenta própria, com uma roldana, para acompanhar a forma na superfície circular.

\section{Curvatura da campana}

A análise realizada, previamente, acerca de algumas fontes determinou a identificação de diferentes técnicas com vários materiais possíveis de serem aplicados. A curvatura da campana é um processo muito delicado, no sentido que um erro nesta fase pode comprometer, completamente, 
todo o trabalho já realizado. 0 processo é realizado com uma ferramenta própria que, por meio de umas guias e de uma alavanca, determina a curvatura desejada. A inserção de um material de suporte dentro da peça evita a criação de quebras, vincos ou rugas, que podem comprometer, quer a performance acústica, quer a competência estética do produto. Trata-se da escolha de materiais com uma temperatura de fusão mais baixa do que a temperatura do material da peça, ou seja, especificamente, trata-se do cobre mas poderia ser o latão. Depois se ter determinado a dobra, o material de suporte é eliminado, fornecendo calor.

Entre os materiais metálicos mais utilizados para acompanhar a deformação da peça, existe o chumbo ou a liga, designada de Cerrobend ou metal de madeira [24]. A desvantagem na utilização deste método é que as temperaturas a atingir para eliminar estes materiais do corpo da peça são altas e arriscam de comprometer o comportamento futuro da campana.

Em muitos casos [25] [26], a curvatura da campana é obtida por meio da inserção de água e sabão. Este processo, conforme como está explicado em sítios de internet de empresas produtoras, inicia-se pelo enchimento da peça com uma solução de água e sabão que é levada a cerca de $-53^{\circ} \mathrm{C}$. Neste processo o gelo não quebra devido à presença do sabão. A utilização das formas limita-se à presença de uma arca frigorífica bastante grande para poder colocar a peça.

Relativamente ao caso do artesão italiano, utiliza-se uma resina designada de "pich" ou betume asfáltico. Este material foi igualmente, encontrado em outros casos e tratado por alguns autores [27]. O problema que se levanta com este tipo de materiais é a pouca facilidade de o encontrar no mercado Português. Este tipo de resina aparece raramente, no sentido que foi substituída por novos produtos que já não reúnem as caraterísticas e as propriedades desejadas. Entre elas a principal no nosso caso ou seja de ter uma boa densidade, de estar a temperatura ambiente em estado sólido e fundir a uma temperatura relativamente baixa.
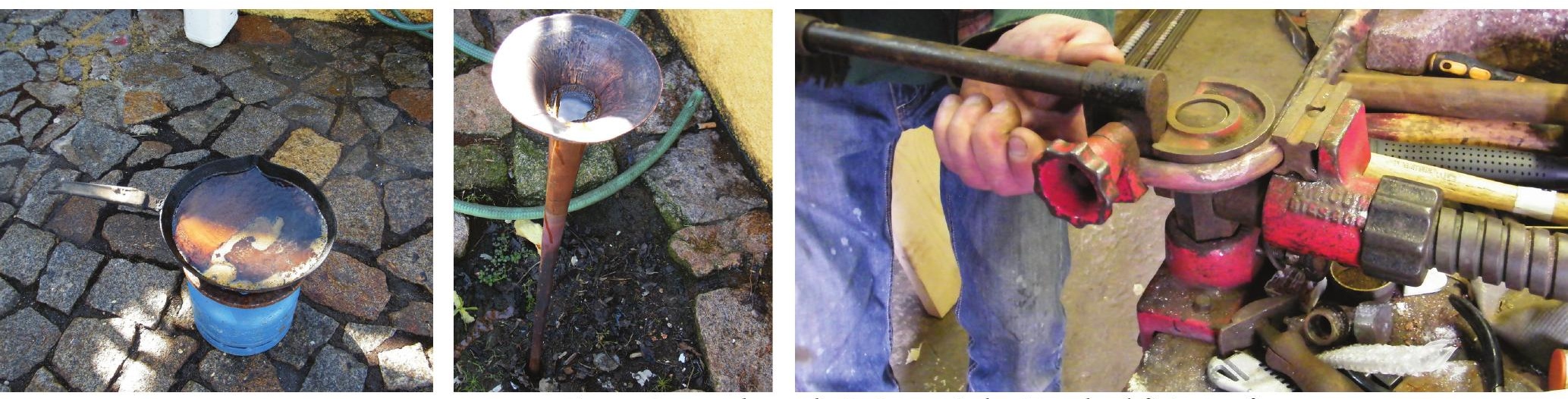

Figura 7 Da esquerda para direita: Preparação da mistura de colofônia e parafina.

Mistura de colofônia e parafina vertida na peça. Processo de dobragem.

Fonte Ermanno Aparo, 2016. 
As condicionantes locais orientaram este estudo para a escolha de uma mistura composta por resina colofônia (90\%) e parafina (10\%), solução já adoptada pelo artesão num processo aplicado, quer para curvar tubos em latão, quer para produzir cornetas e clarinas. A este processo são aplicadas as ferramentas do artesão local.

\section{Resultados e Conclusões}

\section{A importância para o contexto}

Para o contexto, o processo desenvolvido determinou a possibilidade de introduzir uma ação criativa num novo contexto territorial, determinando a inovação. Este tipo de processo desenvolve-se na leitura e na análise das condicionantes que determinam o seu sucesso ou fracasso. Trata-se de um processo de verificação e ponderação acerca, quer das condições existentes, quer das opções selecionadas com o objetivo de garantir um resultado final portador de cultura e de diálogo entre as diferentes forças existentes no território. 0 processo relacionado com o desenvolvimento de um instrumento musical, âmbito complexo e articulado, pretende validar a ação do design [28] na leitura correta e na averiguação contínua às condições produtivas encontradas no território. A interpretação e valorização da atividade produtiva pode ser obtida construindo as condições determinantes para que esta possa atuar num novo âmbito.

\section{A importância para o design}

A disciplina do design, na proposta que Francesco Morace define como "virtuosa" [29], propõe caminhos que podem conciliar o que é tecnológico com o que é cultural, numa complexidade reveladora de um percurso estimulante portador de inovação. A natureza do design, pela sua singularidade metodológica, apresenta uma natureza critica e produtiva que lhe confere um papel criativo e inovador. Neste processo de análise, o design encontra circunstâncias determinantes para a criação de novos cenários de produtos. Neste sentido, a criação de instrumentos musicais pode ser muito mais do que um pretexto projetual. A criação de instrumentos musicais revela-se, assim, uma plataforma complexa para a deliberação e a validação de processos que envolvem sistemas produtivos portadores de cultura e de desenvolvimento do território. 


\section{Referências}

[1] Massaroni, E.; Ricotta, F. (2009). "Dal sistema impresa ai sistemi di imprese. Suggestioni e limiti delle reti d'impresa" in Sinergie N. 80, Settembre-Dicembre 2009, pp .3-29.

[2] Manzini, E. (2016) “Design Culture and Dialogic Design” in Design Issues 32 (1), pp. 52-59. [3] Buono, M.; Pelosi, S. (2011) "Connecting training and design processes: Definition of an effective model for design training” in Strategic Design Research Journal, 3(1). Unisinos, pp.7-12.

[4] Petiot, J.F.; Gilbert, J. (1999) “Aided Design of brass musical Instruments" in Batoz, J.L.; Chedmail, P.; Cognet, G.; Fortin, C. (ed) Manufacturing in Mechanical Engineering '98. New York, Springer, pp.497-504.

[5]http://www.matriznet.dgpc.pt/MatrizNet/Objectos/ObjectosConsultar.aspx?IdReg=147986 acedido em 18/02/16.

[6]http://www.matriznet.dgpc.pt/MatrizNet/Objectos/ObjectosConsultar.aspx?IdReg=39904 acedido em 18/02/16.

[7]http://www.matriznet.dgpc.pt/MatrizNet/Objectos/ObjectosConsultar.aspx?IdReg=39910 acedido em 18/02/16.

[8]http://www.matriznet.dgpc.pt/MatrizNet/Objectos/ObjectosConsultar.aspx?IdReg=40896 acedido em 18/02/16.

[9]http://www.matriznet.dgpc.pt/MatrizNet/Objectos/ObjectosConsultar.aspx?IdReg=40490 acedido em 18/02/16.

[10] Veiga de Oliveira, E. (1982). Instrumentos musicais populares portugueses. Lisboa: Fundação Calouste Gulbenkian.

[11] Silva. S. A., (1992). Editorial, Cadernos de Design ano 1 n². Lisboa: Ed. Centro Português de Design, pp .12-16.

[12] Papanek V. (1971). Design for the real world: human ecology and social change. London: Thames and Hudson.

[13] Manzini, E. (2005) "Un Localismo Cosmopolita" in SDI Magazine - Rivista del Sistema Design Italia, $n^{\circ} 2 / 05$. Milano: Sistema Design Italia, pp .1-6.

[14] Alexander, C. (1977). A pattern language: towns, buildings, Constructions. Oxford, UK: Oxford University Press.

[15] Webb, J. (1988) "The Billingsgate Trumpet" in The Galpin Society Journal. Vol. 41 (Outubro), pp .59-62.

[16] Whitehead, L.; Myers, A. (2004) “The Köhler Family of Brasswind Instrument Makers” in Historic Brass Society Journal vol. 16, pp .89-123.

[17] Lasocki, D. (2010) "New Light on Eighteenth-Century English Woodwind Makers from Newspaper Advertisements" in Galpin Society Journal no 63, pp .73-142.

[18] https://cderksen.home.xs4all.nl/ConnArticle20.html acedido em 28/02/16.

[19] SOARES, Liliana (2012). O designer como intérprete de cenários de equipamentos. Universidade de Aveiro. http://ria.ua.pt/handle/10773/8998, acedido a 28/02/2016.

[20] Cross, N. (2006). Designerly ways of Knowing. London: Ed. Springer.

[21] Jones, J. C. (1992). Design Methods: seeds of human futures. New York and Chichester: John Wiley \& Sons.

[22] http://www.klassodern.ch/ acedido em 04/03/16. 
0 design como método para a implementação de processos produtivos relacionados com a criação de instrumentos musicais em Portugal:

A criação de uma campana de trompete

[23] http://www.gp-wind.com acedido em 04/03/16.

[24] http://www.divitt-trumpets.com/ acedido em 09/03/16.

[25] http://pt.yamaha.com/ acedido em 10/03/16.

[26] http://www.getzen.com/ acedido em 10/03/16.

[27] http://acoustics.org/pressroom/httpdocs/133rd/2amu4.html acedido em 10/03/16.

[28] Aparo, E.; Soares, L. (2007) "O Design como factor de desenvolvimento do terceiro mundo", in Revista Design em Foco, v. IV n.1, jan/jun 2007, Salvador: EDUNEB; pp .101-108.

[29] Morace, F. (2008). Consum-Autori. Le generazioni come imprese creative. Milano: Scheiwiller. 